DOI: $10.5604 / 01.3001 .0013 .2548$

\title{
MODELING OF PROCESSES IN CRUDE OIL TREATED WITH LOW-FREQUENCY SOUNDS
}

\author{
Yelena Blinayeva, Saule Smailova \\ D. Serikbayev East Kazakhstan state technical university, Faculty/Department Information Technology
}

\begin{abstract}
These days new methods of purification of crude oil from paraffin are being sought to improve the quality of oil, reduce its cost and optimize the processes of technological preparation of oil. The paper describes the method of conducting an experiment to study the impact of low-frequency sounds on oil samples of the Zhanazhol field, and presents the results of experiments, the input parameters of the experiment (exposure time and frequency of infrasound), at which the maximum reduction of the kinematic viscosity of oil is achieved. Further study of processes in crude oil under the influence of low-frequency sounds is planned to be investigated in COMSOL Multiphysics ${ }^{\circledR}$.
\end{abstract}

Keywords: crude oil, low frequency sounds, kinematic viscosity

\section{MODELOWANIE PROCESÓW OCZYSZCZANIA SUROWEJ ROPY NAFTOWEJ WYKORZYSTUJĄCYCH DŹWIĘKI O NISKICH CZĘSTOTLIWOŚCIACH}

Streszczenie. Obecnie poszukiwane sa nowe metody oczyszczania surowej ropy naftowej z parafiny, prowadzące do obniżenia kosztów i optymalizacji procesów przetwarzania ropy naftowej. W artykule opisano sposób prowadzenia eksperyment polegajacego na badajacego wplyw dźwięków o niskiej częstotliwości na parametry próbek ropy naftowej pochodzace z pola Zhanazhola. Przedstawiono wyniki doświadczeń, parametry wejściowe eksperymentu (czas ekspozycji i częstotliwość infradźwięków), przy których osiagane jest maksymalne obniżenie lepkości kinematycznej ropy naftowej. Dalsze badania procesów zachodzacych w ropie naftowej pod wplywem dźwięków o niskiej częstotliwości planowane sa w środowisku COMSOL Multiphysics.

Słowa kluczowe: surowa ropa naftowa, dźwięki o niskiej częstotliwości, lepkość kinematyczna

\section{Introduction}

Due to the development of light oil reserves, oil fields with a high content of paraffin hydrocarbons and tar-asphaltene components are increasingly put into operation. Such oil is characterized by high values of viscosity, pour point and density. In the process of production, transportation and storage of highparaffin and paraffin oils, asphalt-resin-paraffin deposits are often formed on the surface of oil equipment, to combat which additional investments are necessary [3].

In recent years, there has been a significant increase in interest in the possibility of using physical processing methods, in particular ultrasonic technologies, which are proposed to be used to intensify the processes of oil production and transportation, and cleaning oil equipment from paraffin deposits [2]. In this paper, we consider the use of low-frequency acoustic waves on crude oil samples to identify the degree of impact of infrasound on the paraffin content in the samples under study.

Mullakayev M. [7] describes the results of ultrasonic treatment of the samples of crude oil with a high content of resins and asphaltenes. As a result of the studies, a decrease in viscosity and pour point was recorded. The efficiency of ultrasonic treatment increased with the increase in exposure time.

The paper [10] gives an account of the effect of ultrasound on the flow of fluid moving through the channel, the size of which is much smaller than the length of the sound wave. As a result of the studies, the change in the viscosity of the liquid and the change in its rheological properties were recorded.

Various approaches to the organization of studies on ultrasonic effects on crude oil are described in papers $[1,4,5,8,16]$. The analysis of these works allowed us to make an unambiguous conclusion about the effectiveness of acoustic stimulation of crude waxy oil to decrease the concentration of wax and improve its fluidity.

\section{Materials and methods}

Oil dispersed systems are typical non-Newtonian fluids. Rheological properties, as well as the shape, size and structure of particles of the disperse phase of the oil disperse system significantly depend on their composition and on the presence and structure of the main structural components, which include paraffins, resins and asphaltenes. As numerous studies have shown, oils with high content of asphaltenes, resins and paraffins have structural and mechanical properties.
It has been shown in [6] that for oil disperse systems the transition from Newtonian to non-Newtonian properties is typical at decreasing temperature. According to modern notions at the increased temperature (above the melting point) wax molecules contained in the oil dispersed system are in the dissolved state and oil is a free disperse or liquid. At decrease in temperature of oil the spatial position of molecules of n-alkanes changes, energy of their thermal movement decreases and dissolving ability of light fraction of oil system decreases. Later on, due to saturation and oversaturation of the paraffin solution, primary crystallization centers are formed and grow. At the temperature close to the oil paraffin crystallization temperature, the size and number of crystalline structures increase, which leads to the formation of a three-dimensional spatial grid over the entire volume of the oil dispersed system, strongly branched alkanes form an amorphous phase. Structural mesh formation is characterized by the appearance of a coherent disperse system with viscoplastic properties.

The nature and peculiarities of structural formation and rheological behavior of high-viscosity waxy oils and natural bitumens were studied in detail in the works of A. Ratov [11-14]. The authors believe that the main reason for the structural formation in high-viscosity oils and natural bitumens, which causes their high viscosity and manifestation of structuralmechanical strength, are the intermolecular interactions of highmolecular fragments of resin-asphaltene components, which are associated with a strong paramagnetism of their polyaromatic structures. It was noted that sharp changes in rheological properties were observed against the background of a smooth change in the chemical composition of oil dispersed systems, which is expressed in a gradual increase in the concentration of resinous and asphaltene components, which is due to the unified physical and chemical nature of structural formation in highviscosity oils and natural bitumens and corresponds to their genetic commonality. It is known that highly paraffinic oils are thixotropic dispersed systems. The phenomenon of thixotropy is expressed in the hysteresis of the rheological curves of the current "stress - shear rate", obtained by increasing and decreasing the shear rate $(\gamma)$, as well as in reducing the effective viscosity $(\mu)$ with increasing $\gamma$. The dependence of $\mu$ on the value of $\gamma$ is associated with the process of destruction of the structure at the increase of the velocity and its restoration at the decrease of $\gamma$.

The authors [15] have studied the ways of reducing the viscosity of the highly paraffinic oil of the Loidminster field. It has been established that mixing of heavy oil with lighter oil leads 
to improvement of rheological parameters and is the most appropriate method of viscosity reduction (by 96\%). Studies were carried out with the addition of ethyl alcohol, which at the same temperature reduced the viscosity by $90 \%$ of the original value. When using a mixture of water and ethyl alcohol, a 35\% decrease in viscosity is observed.

As the influences controlling the structure of the substance, different variants of electric, electromagnetic, magnetic, ultrasonic, pulsating, vibrating fields or their different combinations are usually used. At the same time, the processes leading to both increase and decrease of the degree of orderliness of the structure of oil disperse systems proceed quite easily.

Until the 60s, most researchers believed that sonochemical reactions occur only in water systems. The first successful works on the sound chemistry of non-aqueous systems were carried out in 1963. It was shown that the non-aqueous systems are also characterized by a significant increase in speed and selectivity of sound-chemical reactions. Currently, the possibility of using ultrasound for the needs of the oil industry is widely studied: ultrasonic treatment of wells and formations; increase of oil recovery factor; cleaning of tanks, tanks and parts of oil equipment from deposits. Ultrasonic impact is aimed at changing both physical and chemical properties of oils, which allows for deeper processing and increased recovery of light fractions.

In general, the following ways to reduce the viscosity of oil and oil systems can be distinguished:

1) thermal methods;

2) mixing oil with solvents;

3) adding reagents-depressors and detergents in oil;

4) Removal of structure-forming components - resins, ashatenes, paraffins;

5) processing by physical fields.

The first four methods are well known and comparatively widely used. The use of physical fields, although it has a long history, is still relatively little present in the oil industry. For the most part, for operations related to the physical impact on oil, the extraction of paraffins, resins or asphaltenes from it is not contemplated, but the directed action on the colloidal or intermolecular interaction of the structure-forming components is considered. Here there is an infinite amount of research and patented developments considering ways of applications of this or that radiation or a complex of radiations.

Among a great number of ways to influence viscous liquids by different physical fields, special attention is paid to acoustic fields.

Ultrasonic influence leads to the destruction of polymer molecules, has a dispersing and colloidal chemical action, accelerates chemical processes.

Acoustic vibrations $(f>20 \mathrm{kHz}$ ) are called ultrasonic. Under the influence of ultrasonic vibrations of a varied frequency range there is a change in the state of the processed medium and energy transfer, yet without the transfer of matter. Physical and chemical phenomena taking place in the propagation of acoustic waves are caused by nonlinear effects, including cavitation. An important feature of cavitation is the local concentration of the energy of the ultrasonic field in small amounts, due to which high densities of energy arise [9].

Cavitation means the rupture of the liquid medium in the event of negative pressures in it. Both liquids and solids are subject to stretching, and when a certain pressure is created, their structure breaks, and cavities are formed. Vapors and gases dissolved in the liquid penetrate into the cavities. Liquids are characterized by high strength under tensile stresses.

The presence in liquids of various micro-inhomogeneities, which violate the continuous structure of the medium, significantly reduce its tensile strength. Cavitation also results from the presence of solid particles in real liquids that contain adsorbed gases on their surface. The formation of cavitation bubbles takes place even in the presence of only one microembryo in the test fluid. The tensile strength, or cavitation strength, of a liquid depends on the nature of the substances it contains, the volume and concentration of the gas. The liquid, subjected to significant static pressures, is more homogeneous due to the dissolution of a larger proportion of micro bubbles in it.

The bubbles - cavitation embryos, oscillating under the action of the sound field, gradually increase in size. This occurs as a result of the predominant diffusion gas flow into the bubble as a result of the "one-way" gas diffusion and due to the micro-flows around the bubble, intensifying this process. In addition, under the influence of constant forces arising in the sound field, gas bubbles fusion takes place.

Increased in size bubbles reduce the cavitation strength of the liquid, so a significant impact on the characteristics of its cavitation strength is made by the time of exposure to the acoustic field.

Ultrasonic cleaning, dispersion and a number of other processes in most cases are carried out in liquids with low viscosity, but some chemical processes occur in environments with high viscosity. If the coefficient of viscosity is close to the viscosity of water $\left(\mu \approx 10^{-3} \mathrm{~Pa}^{*} \mathrm{~s}\right)$, the influence of viscosity on the implosion of cavitation bubbles is negligible. Yet, when the coefficient of viscosity is $10^{-2}-10^{-1} \mathrm{~Pa}^{*} \mathrm{~s}$, the action of viscous forces is already beginning to impact the behaviour of cavitation bubbles. By increasing the viscosity to $1 \mathrm{~Pa}^{*} \mathrm{~s}$, which corresponds to the viscosity of glycerine at room temperature, the bubbles are no longer closed and become pulsating.

Another specific feature of a viscous liquid is its high gas content $(\delta \approx 0,05)$, which is explained by the low rate of ascent and removal of gas bubbles from the liquid. The constant presence of relatively large gas bubbles in viscous liquids greatly reduces their cavitation strength.

As part of the study, a hypothesis was put forward about the effect of infrasound on the change in the concentration of paraffin in the crude oil of the Kazakhstan Zaisan field. The reduction of paraffin concentration can be achieved at the account of the lowfrequency cavitation in the studied oil, followed by intensification of chemical reactions.

\section{Conducting an experimental study and its results}

The authors of the study conducted an experiment on the effects of low-frequency sounds on crude oil samples. The experimental studies were based on the theory of experiment.

Experimental studies on the impact of low-frequency sounds on the oil of Kazakhstan fields were carried out with the samples obtained from the Zaisan field of the East Kazakhstan region.

After the experiments were over, the processed crude oil samples were examined in the laboratory of the center for certification tests of automotive fuels and technical oils to determine the viscosity and the pour point of oil.

The sample volume was $0.0005 \mathrm{~m}^{3}$; the frequency of infrasound was $10 \mathrm{~Hz}, 20 \mathrm{~Hz}, 26 \mathrm{~Hz}$; the duration of infrasound exposure was $15 \mathrm{~min}, 30 \mathrm{~min}$, and $60 \mathrm{~min}$.

The control sample of 0.51 volume was not exposed to lowfrequency influence.

As a result of laboratory studies of oil treated with lowfrequency sounds, some changes in the pour point of oil were established. The results are presented in Table 1

The control sample of 0.51 volume was not exposed to lowfrequency influence, the control sample pour point made $-6^{\circ} \mathrm{C}$.

Table 1. The values of the pour point of crude oil

\begin{tabular}{|c|c|c|c|}
\hline No & $\begin{array}{c}\text { Frequency, } \\
\mathrm{Hz}\end{array}$ & $\begin{array}{c}\text { Exposure, } \\
\text { min. }\end{array}$ & $\begin{array}{c}\text { The pour point, } \\
{ }^{\circ} \mathrm{C}\end{array}$ \\
\hline 1 & 10 & 15 & $-6,3$ \\
\hline 2 & 10 & 30 & $-6,5$ \\
\hline 3 & 10 & 60 & $-7,6$ \\
\hline 4 & 20 & 15 & $-8,3$ \\
\hline 5 & 20 & 30 & $-7,9$ \\
\hline 6 & 20 & 60 & $-7,5$ \\
\hline 7 & 26 & 15 & $-8,3$ \\
\hline 8 & 26 & 30 & $-7,6$ \\
\hline 9 & 26 & 60 & $-7,2$ \\
\hline
\end{tabular}


The received results of the experiment allow concluding the following:

1) As a result of the impact of low-frequency sounds in the range from 10 to $26 \mathrm{~Hz}$ on crude oil, a decrease in pour point and some improvement in fluidity at low temperatures were achieved. The greatest decrease in the pour point of oil was recorded at the frequency of $20 \mathrm{~Hz}:-31.7 \%$, the lowest - at the frequency of $10 \mathrm{~Hz}:-13.3 \%$.

2) The greatest decrease in the pour point of oil was recorded at the exposure time of $15 \mathrm{~min}:-37.2 \%$, the lowest - at the exposure time of $30 \mathrm{~min}:-22.2 \%$.

As a result of laboratory studies of oil treated with lowfrequency sounds, changes in the kinematic viscosity indices were established (Table 2).

Table 2. The values of kinematic viscosity at $100^{\circ} \mathrm{C}, 20^{\circ} \mathrm{C}$

\begin{tabular}{|c|c|c|l|l|}
\hline No & $\begin{array}{c}\text { Frequency, } \\
\mathrm{Hz}\end{array}$ & $\begin{array}{c}\text { Exposure, } \\
\text { min. }\end{array}$ & $\begin{array}{c}\text { Kinematic viscosity } \\
\text { at } 100^{\circ} \mathrm{C}, \mathrm{m}^{2} / \mathrm{s}\end{array}$ & $\begin{array}{c}\text { Kinematic viscosity } \\
\text { at } 20^{\circ} \mathrm{C}, \mathrm{m}^{2} / \mathrm{s}\end{array}$ \\
\hline 1 & 10 & 15 & $2.2272 \times 10^{-6}$ & $14.8829 \times 10^{-6}$ \\
\hline 2 & 10 & 30 & $2.1059 \times 10^{-6}$ & $14.9117 \times 10^{-6}$ \\
\hline 3 & 10 & 60 & $2.1156 \times 10^{-6}$ & $15.1556 \times 10^{-6}$ \\
\hline 4 & 20 & 15 & $2.1737 \times 10^{-6}$ & $15.0988 \times 10^{-6}$ \\
\hline 5 & 20 & 30 & $2.1430 \times 10^{-6}$ & $14.8531 \times 10^{-6}$ \\
\hline 6 & 20 & 60 & $2.1420 \times 10^{-6}$ & $14.1374 \times 10^{-6}$ \\
\hline 7 & 26 & 15 & $2.1227 \times 10^{-6}$ & $14.5859 \times 10^{-6}$ \\
\hline 8 & 26 & 30 & $2.1538 \times 10^{-6}$ & $14.1723 \times 10^{-6}$ \\
\hline 9 & 26 & 60 & $2.1616 \times 10^{-6}$ & $14.3682 \times 10^{-6}$ \\
\hline
\end{tabular}

The control sample of 0.51 volume was not exposed to lowfrequency influence, the control sample kinematic viscosity at $100^{\circ} \mathrm{C}$ made $2.1616 \times 10^{-6} \mathrm{~m}^{2} / \mathrm{s}$; at $20^{\circ} \mathrm{C}$ it amounted to 14.9356 $\mathrm{x} 10^{-6} \mathrm{~m}^{2} / \mathrm{s}$.

Figures 1 and 2 show the dependence of the kinematic viscosity of oil on the frequency of infrasound and the time of exposure.

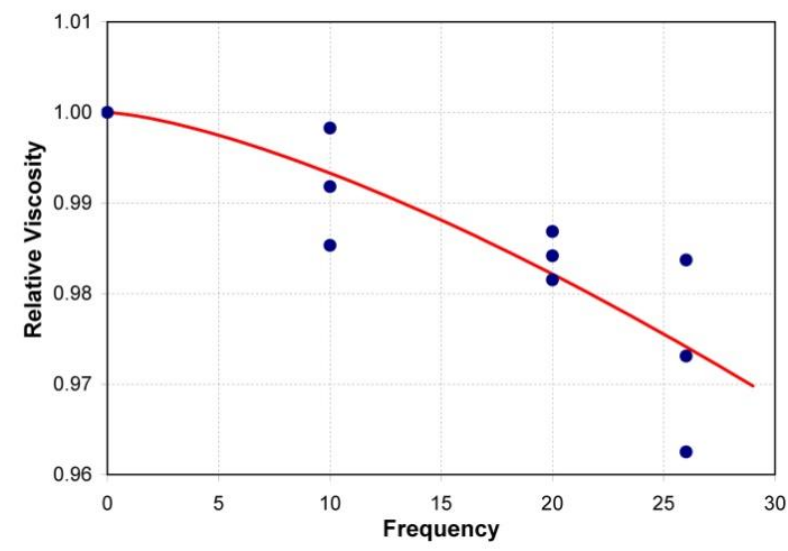

Fig. 1. The dependence of the kinematic viscosity of oil on the frequency of infrasound.

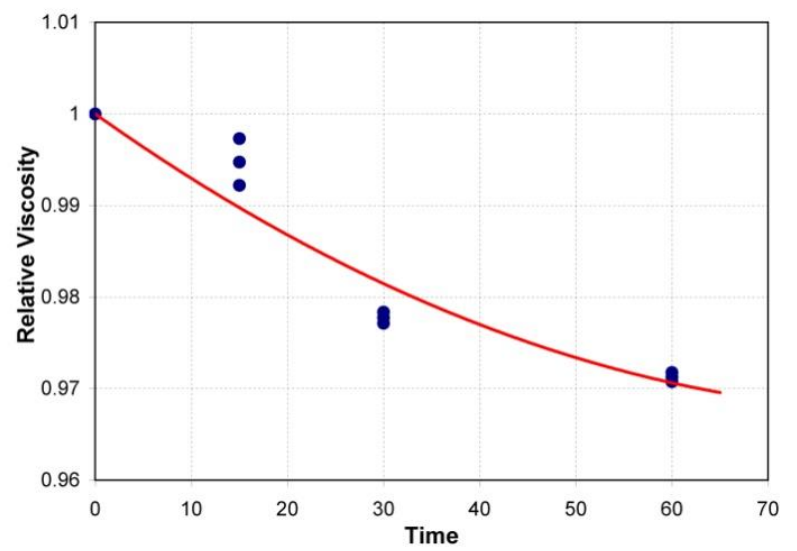

Fig. 2. The dependence of the kinematic viscosity of oil on infrasound exposure time
The results of the experiment allow us to draw a conclusion about the dependence of the kinematic viscosity of crude oil on the frequency and time of exposure to infrasound and the improvement of the fluidity of crude oil at low temperatures.

\section{Further computer simulation}

On the basis of the experimental data it is planned to conduct computer simulation of infrasonic impact on crude oil in COMSOL Multiphysics ${ }^{\circledR}$, the environment of numerical simulation, using the "Acoustics" module. The Acoustics module provides a set of tools for modeling acoustic waves and vibrations in loudspeakers, mobile devices, microphones, sound absorbers, sensors, sonars and flow meters. For more detailed studies, acoustics can be considered together with other physical effects, including structural mechanics, piezoelectric phenomena and hydrodynamics. The COMSOL ${ }^{\circledR}$ software package contains multiphysical connections that allow calculating the performance characteristics of devices and structures as close to real conditions as possible.

A number of interfaces from the "scalar acoustics" group will be used to model classical acoustic phenomena such as scattering, diffraction, radiation, and sound wave propagation. For problems in the frequency domain the Helmholtz equation is used, for research in the time domain - the classical scalar wave equation.

The Helmholtz equation is a differential equation $\Delta u+\lambda u=0$, where $\mathrm{D}$ is the Laplace operator, $\lambda$ is a constant; at $\lambda=0$ the boundary condition passes into the Laplace equation. The boundary condition can be obtained from the wave equation, if the time dependence is described by the $\exp (\mathrm{i} \omega \mathrm{t})$ function, in this case $\lambda=\omega^{2} \mathrm{c}^{-2}$ ( $\mathrm{c}$ is the wave propagation velocity).

For boundary conditions in a bounded domain, ordinary boundary value problems (Dirichlet, Neumann, etc.) are considered. The values of $\lambda$ for which there is a nonzero solution of a homogeneous boundary condition are called eigenvalues of the Laplace operator. For such values of $\lambda$ the solution of the boundary value problem is not unique. Using the Green's function, the boundary value problem can be reduced to an integral equation. In the case of an unbounded domain, the solution of the boundary condition decreasing at infinity is not unique at $\lambda>0$. In this case for discrimination of the only decision additional conditions are set.

Sound waves are the solution of hydrodynamic equations. For an ideal (without absorption) fluid in which the dynamic processes take place at a constant entropy $\mathrm{S}$, these equations are: Euler equation (motion)

$$
\frac{d v}{d t}=\frac{\partial v}{\partial t}+(v \nabla) v=-\frac{\nabla P}{\rho}+f
$$

the law of conservation of mass (continuity equation):

$$
\frac{\partial \rho}{\partial t}=-\nabla(\rho v)
$$

and the equation of state:

$$
\frac{d P}{d t}=c^{2} \frac{d \rho}{d t}, \quad c^{2}=\left(\frac{\partial P}{\partial \rho}\right)_{S}
$$

where $v$ is velocity of liquid particles, $P$ is pressure, $\rho$ - density, $c$ - adiabatic speed of sound propagation, $\mathrm{f}-$ density (per unit mass) of external forces. Here, $d / d t=\partial / \partial t+(\mathrm{v} \nabla)$ denotes the total time derivative, which characterizes the change of the corresponding value on the moving particle of the liquid, as opposed to the partial derivative $\partial / \partial t$, which characterizes the change at a fixed point in space.

The equation of state (3) is actually a form of the law of allround compression in the theory of elasticity, it is easy to see if instead of density $\rho$ we enter the specific volume (per unit mass) $\vartheta=1 / \rho, \Delta \vartheta=-\Delta \rho / \rho^{2}=-\vartheta \Delta \rho / \rho, \Delta \rho=-\rho \Delta \vartheta / \vartheta$ and write equation (3) as: $\Delta p=-\rho c^{2}(\Delta \vartheta / \vartheta)$, where the bulk modulus of elasticity is $K=1 / \rho c^{2}, \rho c^{2}-$ the compressibility of the medium. This very mechanism is responsible for acoustic waves. All other dynamic processes are virtually unaffected by compressibility, so an incompressible fluid approximation is usually used to describe 
them $d \rho / d t=0\left(c^{2} \rightarrow \infty\right)$. In their turn, the sound waves are weakly affected by gravity and Coriolis force included in $f$ and responsible for surface, internal, inertial waves and Rossby waves. Therefore, when considering sound waves, these forces are also usually neglected.

Sound waves slightly disturb the equilibrium parameters of the medium $p_{0}, \rho_{0}$ and $\mathrm{v}_{0}=0$. As a result, substituting into equation (1) - (3) $P=p_{0}+p, \rho=\rho_{0}+\rho^{\prime}$ and leaving under the conditions: $p$ $\ll p_{0}, \rho^{\prime}<<\rho_{0},|\mathrm{v}|=v<<c$ only linear in $p, \rho^{\prime}$ and $\mathrm{v}$ members, we get the linear acoustic equations:

$$
\frac{\partial v}{\partial t}=-\frac{\nabla p}{\rho_{0}}, \quad \frac{\partial p}{\partial t}=-\rho_{0} c^{2} \nabla v
$$

which, considering the equilibrium density of the medium constant ( $\rho_{0}=$ const), are easily reduced to the wave equation:

$$
\Delta p-\frac{1}{c^{2}} \frac{\partial^{2} p}{\partial t^{2}}=0
$$

where $\Delta$ - Laplace operator, $\Delta=\partial^{2} / \partial x^{2}+\partial^{2} / \partial y^{2}+\partial^{2} / \partial z^{2}$ in Cartesian coordinates. For harmonic waves, when the time dependence in $p$ and $\mathrm{v}$ is given by the factor $\exp (-\mathrm{i} \omega t)$, the expression (5) transfers into the Helmholtz equation:

$$
\Delta p-k^{2} p=0
$$

where $k=\omega / c, \omega-$ wave frequency. Vector $\mathrm{I}=p \mathrm{v}$ it is a vector of acoustic power flux density (energy per unit of time). This is easy to understand for physical reasons: $p$ n $d S$ - the sound pressure force acting on the platform $d S$ with the normal n, $p v n d S$ - the power of this force, therefore, the vector of the power flow density will be the value $\mathrm{I}=p \mathrm{v}$.

\section{Conclusions}

In the conducted research the analysis of methods of acoustic influence on crude oil allowing to reduce concentration of paraffin in it has been carried out. The experimental studies of the effect of low-frequency sounds on crude oil in order to reduce the paraffin content in the oil have been described. The prospects of further research based on the results of experiments by conducting computer simulation based on the finite element method in the COMSOL Multiphysics ${ }^{\circledR}$ environment have been presented.

\section{Acknowledgements}

This work supported within a grant of the Ministry of Education and Science № 35-293-18 "Analysis and modeling of the effect of low-frequency sounds on the change in the sulfur content and the viscosity of crude oil from Kazakhstan's fields".

\section{References}

[1] Abramov V., et al.: Sonochemical Approaches to Enhanced Oil Recovery. Ultrasonics Sonochemistry 25/2015, 76-81.

[2] Anufriev R.: Influence of Ultrasonic Treatment on Structural and Mechanical Properties and Composition of Oil Disperse Systems. Thesis for the degree of candidate of chemical Sciences. Russia, Tomsk 2017.

[3] Baydeldina O., Daribaeva N., Nuranbaeva B.: Features of the Structure and Properties of Crude Oils of Kazakhstan Influencing the Effectiveness of
Interventions in the Fight against Paraffin Deposition. Modern High Technologies 4/2015, 100-106.

[4] Ershov M., et al.: Mathematical Processing of Results of Experiments on Ultrasonic Effects on the Viscosity of the Oil. Vestnik of SSTU 1/2012, 250 253.

[5] Guoxiang Y., et al.: Application of Ultrasound on Crude Oil Pretreatment Chemical Engineering and Processing 47/2008, 2346-2350.

[6] Iktisanov V., et. al.: Rheological studies of paraffin oil at different temperatures. Colloidal journal 61(6)/1999, 776-779.

[7] Mullakaev M., Volkova G., Gradov O.: Effect of Ultrasound on the ViscosityTemperature Properties of Crude Oils of Various Compositions. Theoretical Foundations of Chemical Engineering 49(4)/2015, 287-296.

[8] Mullakaev M., et al.: Development of Ultrasonic Equipment and technology for Well Stimulation and Enhanced Oil Recovery. Journal of Petroleum Science and Engineering 125/2015, 201-208.

[9] Nemchin A., et al.: Influence of Cavitation Influence on Hydrocarbon Fuel. Prom. Thermotechnics 24(6)/2002, 60-63.

[10] Prachkin V., Mullakaev M., Asylbaev D.: Improving the Productivity of Wells by Means of Acoustic Impact on High-Viscosity Oil in the Channels of the Face Zone of a Well. Chemical and Petroleum Engineering 50/2015.

[11] Ratov A., et. al.: Features of structure formation in high-viscosity paraffinic oils. Chemistry and technology of fuels and oils $1 / 1995,22-24$.

[12] Ratov A.: Mechanisms of structure formation and anomalies of rheological properties of high-viscosity oils and bitumen. Russian chemical. journal 39(5)/1995, 106-113.

[13] Ratov A.: Physical and chemical nature of structure formation in high-viscosity oils and natural bitumen and their rheological differences. Petrochemistry 36(3)/1996, 195-208.

[14] Ratov A., et. al.: Structure formation in high-viscosity oils and natural bitumen Chemistry and technology of fuels and oils 3/1997, 36-38.

[15] Shadi W.: Heavy crude oil viscosity reduction and rheology for pipeline transportation. Fuel 89/2010, 1095-1100.

[16] Shedid A.: An Ultrasonic Irradiation Technique for Treatment of Asphaltenes Deposition. Journal of Petroleum Science and Engineering 42/2004, 57-70.

Ph.D. Yelena Blinayeva

e-mail: blinaeva-helen@mail.ru

The area of scientific interest is the use of lowfrequency acoustic fields to influence various media (gas, crude oil) in order to identify the degree of influence of infrasound on the processes occurring in the medium under study.

Head of research in the framework of grant financing of the Ministry of Education and Science of the Republic of Kazakhstan. She has more than 30 publications of scientific articles in magazines in Kazakhstan, Russia, Ukraine. Author of articles in journals indexed in Scopus.

She participated in international conferences and seminars (Turkey, Bulgaria), with a speech at breakout sessions.

ORCID ID: 0000-0001-7251-3292

\section{Ph.D. Saule Smailova \\ e-mail: Saule_Smailova@mail.ru}

S. Smailova is currently a lecturer at the Departmen of Information Technology. She is a co-author over 60 papers in journals, book chapters, and conference proceedings. Member of Expert Group in the Computer Science specialization of IQAA. Her professional interests are teaching, artificial intelligence, software engineering, data processing.

ORCID ID: 0000-0002-8411-3584

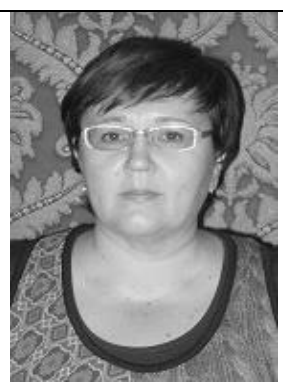

otrzymano/received: 15.05 .2019

przyjęto do druku/accepted: 15.06 .2019 